\title{
Ageing, ageism, and lost honor: narratives of Arab elders in Israel
}

\author{
By SHLOMIT MANOR*
}

\begin{abstract}
This study examines how Arab elders in Israel experience old age and speak about ageism, old age, and loss of honor. Interviews were conducted with 25 Arab men and women, both Muslims and Christians, between the ages of 63 and 86. The findings indicate that despite Arab society being a familial and traditional society, informants experience ageism and feelings of loss of respect and status in both the public and private spheres. The findings reveal a multilayered discourse, inconsistent and incoherent, riddled with internal contradictions about honor, exclusion, ageism, and its absence. This discourse reflects Arab society's ambivalence about the ongoing processes of modernization on the one hand, and the desire to preserve traditional family values and the status of older populations on the other. The issue of ageism within Arab society in Israel has not thus far drawn much attention in the field of gerontological research, and this study therefore aims to fill this gap.
\end{abstract}

Keywords: ageing, ageism, Arab Society, honor, older people 
International Journal of Ageing and Later Life

\section{Introduction}

Ageism, as defined by Butler $(1969,1975)$, is a discriminatory attitude toward old people due to their advanced age, based on prejudice and stereotyping. While any age group can be discriminated against as belonging to an age category, Butler (1975) referred particularly to discrimination directed at older people. He claimed that ageism is more prevalent among the young than the old and that it diminishes as people grow older because their perspective on aging becomes more positive. Additional research has supported this claim that young people tend to hold more ageist attitudes than older people (Rupp et al. 2005). However, other studies have pointed to the existence of self-ageism among older people toward their peers (Bodner et al. 2011). Ageism can be manifested at both the individual and institutional level and may include a variety of behaviors such as avoidance of contact or connection with older people, denial of age, display of negative attitudes toward older people, and arrogant or patronizing behavior (Bodner 2009; Bodner et al. 2012; Doron 2008; Tornstam 2006, 2007).

The literature dealing with ageism presents various conceptions regarding its cultural aspect. Some researchers have argued that ageism is a universal phenomenon that exists in every society and every culture and is not unique to any, while others have claimed that the ageism phenomenon is closely linked to culture (Chi 2011; Cuddy et al. 2005; Löckenhoff et al. 2009).

In recent years the ageism discourse has entered into gerontological research, and the number of studies on the topic has grown. This study joins the discussion over the question of the extent to which the ageism phenomenon is prevalent in a traditional society - in this case Arab society in Israel.

The literature on this topic has generally used quantitative methods, for example, the test developed by Rosencranz and McNevin (1969), which examines the connection between age and a variety of attributes. Another famous measurement test constructed by Palmore (1977) comprised 25 statements assessing the levels of knowledge and ageist behavior toward older people. Palmore (2001) later published the ageism survey, a tool for measuring actual expressions of ageism by examining the extent to which older people have been exposed to them. During the 1990s, the 
Ageing, ageism, and lost honor

"Fraboni scale of ageism" (FSA) (Fraboni et al. 1990), which examines ageist positions, antagonism, and discrimination, became the most common measurement tool in research on ageism. Subsequently, the discussion about measuring ageism expanded, and Tornstam $(2006,2007)$ offered additional possibilities for typologies and measurements. The current study, on the contrary, examines the ageism phenomenon as a subjective experience, as it is grasped by older people themselves, and the way they talk about ageing. I use qualitative methodologies to expose the narrative that shapes the discourse of ageing in a traditional society, in this case, Arab society in Israel.

\section{Ageism: Pan-Cultural or Culture-Dependent Phenomenon?}

Culture has an appreciable influence on the way we grasp age and ageing and the way we treat old people (Aboderin 2004; Koren 2013). Some have seen ageism as a universal, objective phenomenon that is based on age categorization and is independent of time and place because in every culture there is a category of old age (Hazan 1994, 2002, 2013; Iversen et al. 2009). Others have argued that the scope of ageism, as too the general attitude toward the phenomenon of ageing, is culture dependent, and therefore its manifestations vary from culture to culture (Aboderin 2004; Chi 2011; Koren 2013; Löckenhoff et al. 2009; Palmore 2004). Palmore (2004) referred to the cultural aspect, arguing that prejudice-based ageism is closely linked to cultural stereotypes and is a relative, culture-dependent concept. He claimed that ageism is more prevalent in modern Western cultures that encourage achievements and innovation and therefore show a preference for young people; in traditional cultures, such as Eastern cultures or Arab culture, ageism is much less prevalent. A similar finding can be found in a comprehensive comparative study of 26 countries by Löckenhoff et al. (2009) about cultural influences on the perception of age and ageism.

The picture that arises from the existing research is that in Eastern cultures and cultures of a traditional nature, attitudes toward older people and ageing tend to be more positive than in Western societies (Chonody \& Teater 2016; Macia et al. 2009; Yun \& Lachman 2006). Furthermore, as Chi (2011) noted, in Western society there is, primarily, an appreciation of an older person's degree of independence, whereas in Eastern society the 
International Journal of Ageing and Later Life

dependence of the aged on the young is accepted with understanding. In addition, fears of ageing are much more common in Western societies than in Eastern and traditional ones. In a comparative study of Morocco and France, Macia et al. (2009) painted a similar picture about stereotypes of age and respect for older people.

In direct contrast to these findings, North and Fiske (2015) found that Eastern cultures hold similarly negative attitudes toward older people as Western cultures. Despite the expectation of respect for the aged in Eastern cultures, this is not always realized and is not necessarily translated into practice. As Arab society in Israel is exposed to both Western and traditional influences; this study joins the literature dealing with the phenomenon of ageism in traditional society and examines its prevalence in Arab society in Israel.

\section{Self-Ageism and Social Identity: A New and Foreign Concept in Arab Culture}

As people grow older and move from a younger to an older age group, ageism migrates with them but can now be directed at themselves as the older group (Levy 2003). This phenomenon is called "self-ageism" (within-generation), that is, stereotypical and negative views of people from one's own age group (Bodner 2009; Bodner et al. 2011, 2012). Paradoxically, spending time with older people in one's own age group contributes to self-ageism. Furthermore, research findings have indicated that older people who live with other older people tend to perceive themselves as younger than their chronological age and belonging to a younger age group (Manor 2017). It is, remarkably, older people themselves who formulate ageist positions toward their peers while denying their own age and treating the group to which they belong stereotypically (Bodner 2009; Gamliel \& Hazan 2006; Manor 2017). Support for this argument that older people hold negative views of their own age group, despite being completely unfamiliar with the word ageism, was also found in other studies (Minichiello et al. 2000).

One of the explanations for ageism lies in Tajfel and Turner's (1979) theory of social identity (Tajfel 1981). According to this theory, identity is a combination of personality traits and environmental factors. Social identity reflects one's belonging to various social groups, some of which 
we identify with and to which we feel a sense of belonging, for example, gender, nation, religion, ethnicity, and profession, and others with which we do not identify. A sense of belonging helps people define themselves in relation to a certain group and be acknowledged as a member of that in-group, at the same time marking others as not belonging and therefore making up the out-group. Social identity is constructed through finding differences and conducting comparisons between those who are with us in the group and those who are outside our group, with the aim of strengthening our belonging to the group and vitalizing our social identity (Tajfel \& Turner 1979, 1986). Belonging to a certain social group is significant for the individual's identity. People therefore strive to define and describe their group in a positive manner, so they can identify with it and feel a part of it, while those outside the group are perceived negatively.

The categorical division into younger and older people is manifested in the fact that younger people identify with their own age group, have a positive view of their social group, and look upon the out-group, namely, older people, as inferior. Older people, on the contrary, see their own group as inferior and show a preference for the out-group, namely, younger people (Levy 2003). The categorical division by age differs from all other distinctions. Gender, ethnicity, nationality, or religion tend to remain fixed throughout life, so one's group belonging does not change; however, all young people will become older people and be part of that social category which they may presently look upon negatively as inferior.

According to Tajfel and Turner's (1979) social identity theory, rejection and lack of identification are also among the forces that shape the individual's identity and self-image. In other words, belonging to a group of low social status, which does not inspire identification, sparks abhorrence and rejection and can influence a person's identity. This is, indeed, the case among older people who do not identify with members of the group to which they belong but would prefer to belong to a younger age group.

This is where self-ageism comes into play, when older people are unable or uninterested in identifying with the group to which they themselves belong. They continue to perceive ageing negatively and to hold negative views and stereotypes of ageing even once they themselves are part of this social group (Levy 2001). Resistance to ageing, which is supported by social norms, reinforces self-ageism (Bodner et al. 2012). In this article 
International Journal of Ageing and Later Life

I examine the ageism phenomenon as expressed through the personal experience of Arab elders with reference to unique cultural elements which are somewhat missing from the social identity theory.

\section{Arab Society in Israel}

The Arab population in Israel is approximately 1.8 million, constituting $20 \%$ of Israel's total population (CBS 2016). Arab society is heterogeneous and includes Muslims, who are the largest group, Christians, and Druze. Despite modernization processes, Arab society is still considered a traditional, familial, and patriarchal society. The Arab family follows strict codes of honor and loyalty. Modernization hasn't changed the expectations of adult children regarding responsibility and care for their ageing parents, and respect for elders is still inculcated during the socialization process. Moving an older person from their home to an assisted living facility, for example, is grasped as deviant in Arab society. It is done only when there is no other choice and the older person cannot be cared for in their home (Khalaila \& Litwin 2012; Lowenstein et al. 2007). Arab culture emphasizes the importance of the family, mutual dependency, social responsibility, and familial solidarity toward elders (Khalaila \& Litwin 2012; Lavee \& Katz 2003).

The literature on Arab society's attitude toward ageing and older people rests, in large part, on the theory of modernization (Aboderin 2004; Azaiza \& Croytoru 2010; Khalaila \& Litwin 2012; Litwin \& Zoabi 2003). It is commonly argued that modernization processes, which impact many realms of life, have caused, among other things, changes in attitudes toward elders and in the structure of the family unit. This is manifested in a weakening of the extended family and a strengthening of the nuclear family. These changes have turned caring for the aged into a burden, evident in a decline in children's willingness to care for their ageing parents. Modernization has prompted a drop in the status of elders, who have shifted from central and respected figures with power and authority to weak, vulnerable, and dependent figures devoid of any authority (Khalaila 2009; Khalaila \& Litwin 2012; Litwin 2006; Lowenstein \& Katz 2000).

Arab society in Israel has a twofold cultural affiliation: on the one hand, with a traditional society and its values and on the other, with the 
Ageing, ageism, and lost honor

modern Western society in which it is located. This duality extends to almost every aspect of life: social, economic, political, cultural, religious, and familial (Smooha 1990). Arab society is a traditional society undergoing a process of modernization. Some have argued that it is a society in transition from a collectivist to an individualistic orientation. The latter brings the individual to the fore and gradually pushes aside the values of the extended family and mutual responsibility, which has an impact on the social status of older people (Gliksman \& Litwin 2011).

\section{Methodology}

The goal of the study was to examine the ageing experience and the ageism phenomenon from the viewpoint of those experiencing it. For this purpose, I used qualitative methods, to assess the subjective meaning of the studied phenomenon. I therefore take an interpretative phenomenological approach, seeking to elicit the essential experience as grasped by the individual, on the assumption that the experiencing itself structures the worldview of that subject.

The phenomenological method is most suitable for examining the meaning and interpretation that individuals ascribe to a certain phenomenon or experience. In this case, the phenomenological method enabled me to excavate the interpretations that the informants ascribed to ageing, their lives, and familial relations during this period (Creswell 2012; Denzin \& Lincoln 2008). Following Russell, I maintain that "all research is a form of storytelling" (2007: 173) and like her, I also looked for the "stories older people tell about themselves" rather than older people as object of stories told by others.

\section{Participants}

The participants in the study included 25 Arab interviewees, 15 women and 10 men, Muslims and Christians, and two women members of the Ahmadi community. About half of the interviewees (13) are from four different villages, and the others (12) are city dwellers. I chose a large mixed city, Haifa, and a medium-sized mixed city, Akko. The ages of the interviewees ranged from 63 to 86 . Despite their wide age range, I referred to the interviewees as one category due to similar characteristics in terms 
International Journal of Ageing and Later Life

of health status. Although they function independently and do not need daily assistance, a large proportion of the interviewees, especially the Muslims ( $80 \%$ of them), suffer from chronic health conditions, such as diabetes, obesity, or high blood pressure. Among the male interviewees, about $75 \%$ smoke and suffer from various chronic lung diseases.

Most of the men (eight) were married, while the other two were widowers. Contrarily, most of the women (nine) were widows, while four were married and two unmarried. All of the interviewees, with the exception of the two unmarried women, have children and grandchildren.

In terms of their economic status, the interviewees were asked what their main source of income is. The findings indicate that more than half $(55 \%)$ rely on welfare allowances as the main source of income, and, in terms of social class belonging, they can be defined as low and very low class. Less than half $(40 \%)$ rely on their pension payments and thus can be defined as middle class. Three were defined as upper class. (Class distribution is based on data on education, occupation, and sources of income.)

The Arab population in Israel is heterogeneous and includes several groups. However, despite the differences between Christians and Muslims in terms of economic status, level of education, participation in the labor market, fertility rates, and so on, for the current study I consciously chose to relate to the Palestinian Arab society as a single entity. This is because family and respect for family members are a central value in Arab society as a whole, regardless of religion (Fogiel-Bijaoui 2002).

\section{Data Collection}

The data were collected by means of a semi-structured in-depth interview, allowing for a combination of predetermined questions and the flexibility and freedom to develop a dialogue and raise additional questions in the course of the interview. The interviewees were located by approaching organizations such as the National Insurance Institute or senior centers, which directed us to potential interviewees. Most of the interviews (75\%) were conducted in the interviewees' homes, the others in a side-room in the senior center reserved for that purpose. The interviews lasted an hour and a half on average. They were conducted face to face, with no family members present. All the interviews were recorded by consent and later transcribed. 
Ageing, ageism, and lost honor

The interviews were sometimes conducted in Arabic with the help of a simultaneous translator who was present during the interview, and sometimes in Hebrew, when an interviewee felt comfortable with the language. Conducting an interview in a language that is not the interviewee's mother tongue has its advantages and shortcomings (LomskyFeder \& Rapoport 2007). As my command of Arabic is not at a high level, I asked the translator and an additional Arab scholar to examine my interpretation of what had been said at the analysis stage, to ensure that it is not culturally biased.

The literature dealing with the asymmetrical power relations between interviewer and interviewee emphasizes the position of power that the interviewer holds which stems from the fact that the researcher is most often of a higher class in the social hierarchy (Bourdieu 1996; LomskyFeder \& Rapoport 2007). As I am Jewish, such asymmetry undoubtedly marked some of my meetings with interviewees, leading sometimes to suspicion of me on their part. This suspicion dissipated in the course of the interviews and I eventually gained their trust. All of the citations below appear under pseudonyms to conceal the interviewees' identities and protect their privacy.

At the start of each interview I emphasized to the interviewees that it was being conducted for research purposes only and assured them that their anonymity would be strictly protected. I also clarified that they could stop the interview at any stage and if, when it ended, they should regret it, I would make no use of the recorded materials. This study has been certified by the College Ethical Committee.

\section{Analysis of the Findings}

Analyzing the findings of a phenomenological study is a process of arranging and structuring the entirety of the information collected while breaking down the data into segments and parts and putting them back together in a different order to understand their significance (Creswell 2012). On the basis of the phenomenological approach, and as suggested by Giorgi (1997), the analysis of the interviews was conducted in several stages. First, I read each interview separately to identify preliminary categories. In the second stage, I analyzed and divided each interview into units of meaning, to create clusters of information that appear to belong to 
International Journal of Ageing and Later Life

the same phenomenon, with the aim of identifying important themes and subthemes. In the third stage, I conducted a comparative analysis through a latitudinal reading of all the interviews according to the division into categories previously assembled. In this way, broader super-categories, that is, central themes, were constructed. The organizing principle for the presentation of the findings below is based on the major themes that emerged from the interviews.

\section{Findings}

\section{Vanishing Honor: "Age Has Ceased to be a Social Status"}

Respect for older people is considered one of the pillars of Arab society and a central value. However, the respect and high status that older people enjoyed in the traditional society are today mainly a thing of the past. Today, many older people lack power and honor, do not have any role or status, and are relegated to the margins of the clan or extended family, as has been noted by Azaiza and Brodsky (2003) and Khalaila and Litwin (2012). An informant, Diana (aged 70), expressed it succinctly: "Age has ceased to be a social status... Once, the older person was master of the neighborhood, everyone respected and listened to him. Not anymore. People pass by an older person in the neighborhood and don't even say hello." In a similar spirit were remarks made by another informant, Meron (aged 81), the pastor of a Christian congregation in a village in northern Israel: "Today it's not like it used to be. Today I feel that the attitude towards me is: 'Who are you that I should consult with you at all? Who do you think you are, what do you understand?'"

Arabic is rich in sayings and parables that tangibly express the changes society has undergone in the status of both younger and older people. An informant, Um Ziad (aged 73), for example, spoke of a younger generation that is never satiated, never satisfied or content with what they have, a materialistic generation that wants more and more, that does not listen to the advice of older people and does not appreciate their experience: “There comes a generation that goes out and doesn't return, that eats but isn't satisfied, that is given advice but doesn't listen." To illustrate the change in the status of older people, another 71-year-old informant 
Ageing, ageism, and lost honor

said: "In the past, it was best for anyone who didn't have an older person to buy one; today, anyone who has an older person at home would be best to throw them out and hide them in the well."

Nostalgia for times past when it was much pleasanter to grow old came up in a large number of interviews. Almost $80 \%$ of the informants spoke of the honor and respect that older people used to be accorded. They described the past as a time when older people enjoyed high status. This was attested to by an informant, Omar (aged 69), who was a school principal for many years: "I treated my father with respect. I can't recall even one time, one time, that I raised my voice or yelled at my father. Not ever. Today there are many such people who yell at their parents."

This may be a fantasy based on subjective memory and idealization of the past. The reality perhaps was different. However, fantasy or reality, the dominant narrative in the discourse on honor refers mainly to it having gone missing over the years, the honor and respect accorded to older people in the past. The informant pastor Meron said: "Once the older person was looked upon as someone wise, who is savvy, who is familiar with society. Today it's exactly the opposite."

Similar sentiments were expressed by the informant Emir (aged 78), but with an interesting twist when comparing Arab and Jewish society: "The respect is gone, oh that there should be respect today, in my times there was respect. Fifty years ago there was respect, but now it's vanished. Maybe it's because of the integration with Jewish society; we've become integrated with the Jewish society." In Emir's view, the change in attitudes toward older people was caused by influences from the Jewish society within which his Arab society is situated. Jewish society is considered modern and Western relative to Arab society, which is considered conservative in everything relating to norms of behavior and relations within the family. The same sort of comparison came up in two other interviews when I asked about the possibility of moving an older person from their home to an assisted living facility. In both cases the answer was an indignant refusal, and the comparison to Jewish society was meant to demonstrate how different Arab society is from Jewish society in its regard for older people. Both informants claimed that whereas Jewish society forsakes its older people, does not respect them, and sends them off to facilities for the aged, Arab society treats its older people much more respectfully and befittingly. The informant Sabrin (aged 72), for example, 
International Journal of Ageing and Later Life

who lives in a village in northern Israel and had only 1 year of schooling, said: "What do we need a facility for the aged for? What are we, Jews?"

Despite the idealization of the past, when the informants were asked whether they would want to return to the past if they could travel through time, almost all replied they would not want it: "I wouldn't say that I want to go backwards; that's all in the past." Only one informant, Sophie (aged 63), a widow who works as a seamstress, answered the question affirmatively, saying: "Yes, I really like the way life used to be. There was respect, things were better. The family was strong and united. Today the families are less united, they're weak. There are no families that live together."

\section{Technology Is to Blame for Loss of Honor}

The modernization processes affecting Israeli society have not bypassed Arab society and have brought about changes in many realms of life. In the framework of these processes, Arab society has become exposed to new technologies such as multichannel cable TV, smartphones, computers, the Internet, Facebook, WhatsApp, and so on. All of these factors have had a significant impact on the status of older people, as the informant Lara (aged 71) reported:

\footnotetext{
Today the kids see all sorts of things on television and they become smarter than the older people. Once the older person was the smartest, now the kids are smarter. Once because the older person was the smartest nobody could argue with them. Today younger people and older people argue. For every word an older person says, the kids have something to say. Once it wasn't that way. In the past older people had the last word and they had the privilege of deciding everything. You didn't argue with them. Today they argue. Even small kids argue with older people. Our generation is different from today's generation. Once there wasn't any television, there were no telephones. Today everything is different.
}

The belief in older people's superior wisdom, due to their greater experience and knowledge than younger family members, no longer exists. Many of the informants blame iPhones, WhatsApp, Facebook, and so on for the decline in respect for older people, as the informant Sophie explained: “A woman today doesn't stay at home to care for her motherin-law or her mother. She has a cellphone, she has Facebook, and there's no time for the older person sitting beside her." 
Ageing, ageism, and lost honor

In the past older people were considered to have vast knowledge and their life experience translated into status and appreciation. In the modern age of advanced technology, older people who don't know how to turn on the cable box or how to use Facebook or WhatsApp have lost their status. The younger generation no longer seeks out older people's advice and, paradoxically, older people are forced to consult with the young. An informant, Jackie (aged 67), for example, complained: “They don't consult with us, for them our experience is unimportant. They even look at us the other way around, that we're an outdated generation that doesn't understand anything, with all the technology and the shifts that have occurred and the development and social and technological changes."

Technological development and accelerated innovation, which have driven the decline in older people's value, have changed the balance of power and the allocation of roles. Thus, despite their advanced age, elders have become dependent, while younger people have become the knowledgeable ones with decision-making power. Advanced age no longer brings with it status and standing as in the past, no longer attests to wisdom or knowledge, but rather to a dearth of them, as the informant Emir related: "On topics relating to technology I turn to the kids, because it's a different generation, and for them it's very easy. Even my nine years old granddaughter uses a cellphone. They know everything; it's an entirely different generation." Emir went on to say that in his opinion the change occurred because of changes happening in Arab society in general, changes that affected mainly the young:

We live in a society of alienation, it's too bad but that's the way it is. It's a big crisis in Arab society (...) This generation today is preoccupied only with itself, it's completely selfish. Today the young people want only for themselves; they don't contribute and don't give. True it's an advanced generation, educated, a generation that has all sorts of possibilities, but it loves only itself. That's the way it is, there's nothing to do.

Mixed messages seem to emerge from these statements expressing two different voices. These remarks convey an accusation leveled against the younger generation, against materialistic Western society, modernization and technology that have penetrated traditional Arab society, changed 
International Journal of Ageing and Later Life

its hierarchy of values and thereby influenced the behavior of the young. At the same time, these remarks express an acceptance of the fact that the times and society have changed, and the process is inevitable. Emir represents other informants in the blame he lays on the West, which fomented these cultural and social changes:

Young people have changed. It comes from the West, not from our society. They are imitating the West. Today technology, the computer, that's what's important. Today if you don't understand how to turn on the telephone, how am I going to respect you?

\section{Self-Ageism: "I Don't Like Being with Older People"}

Ageism, as defined by Butler (1969), is based on prejudice and negative stereotypes and is related to how we perceive age. One manifestation of ageism is avoidance of and an unwillingness to connect or be with older people as well as disregard and repression (Bodner 2009). In Arab society where older people are regarded as the head of the family and central figures, avoiding relations with them is considered unacceptable behavior. Nonetheless, a third of the informants told of an experience in which they felt that people did not want to be in their company, did not want to sit beside them and talk with them. An informant, Renee (aged 67), said: "I ride on the buses and I frequent public places and I see it. Sometimes there is, I don't want to say chutzpah [Yiddish/ Hebrew term for cheek or audacity], but there is no respect for the older person. Sometimes, if he's too old they even complain that he's bothering them."

Not only are the young said to have a negative view of old age, but older informants themselves were found to subscribe to the same view and see old age as weakness, as the informant Muhamad (aged 83) explained: "Old age is weakness. Old people are weak." Due to this perception, not only do the young avoid being with older people, but older people too are disinclined to be in the company of other older people, despite sharing the same age. The informant Sally's (aged 66) story about an experience she had with her mother when she tried to persuade her to engage in activities at the senior citizen club attests to the existence of self-ageism and demonstrates the intensity of older people's disinclination to be in the company of their peers: 
Ageing, ageism, and lost honor

I once took my mother, when she was still alive, to the club. I sat with her but she didn't like it at all and didn't want to go there anymore. I asked her, why? She said to me because everyone here is old. She doesn't like being with old people. She likes being with young people. When you're in surroundings with old people you feel old, when you're with young people you feel young.

The older people themselves thus become complicit to the same ageist perception that views old age negatively and buttress the negative stereotypes of old age. When they do not want to be with older people, simply because they do not want to be in the company of others like them, they are expressing within-generation ageism. The informant Omar, for example, does not want to participate in activities that are identified with old age and stated: "I don't like it when they keep us occupied gluing things. Why don't they build a swimming pool or sports club? I don't like doing arts and crafts for older people."

Ageism is connected to how one accepts old age and the way people perceive themselves and their age. A complex picture arises from the interviews as to the way in which the informants perceive old age and themselves. The vast majority $(95 \%)$ have a religious conception of the process of ageing, which is of assistance in reconciling oneself to and coming to accept old age as a stage of life, a natural and inevitable process, and God's will, as they reported: "It is Allah's will"; "However God wills it, everything is from above"; "However God decided and planned, thus it shall be."

Despite the belief that everything is in God's hands and done in accordance with his will, none of the informants under the age of 70 defined themselves as old and none of them wants to be old. Furthermore, they hope not to reach old age and would prefer that Allah takes them before they reach that stage, as the informant Lara attested: "May God take me before I become old, what's the use of growing old? It's not good to grow old, living until 80 is enough."

\section{Honor in Public Versus Private Space}

One of the most prominent findings to emerge from the interviews was a dual reference to honor: on the one hand, the mention of honor in the public space and on the other hand, the lack of honor in the private space. 
International Journal of Ageing and Later Life

At times this distinction was reversed and the honor moved to the private space and disappeared from the public space.

The public honor was heard when the informants were asked questions about society in general, and not them specifically, for example, whether they feel that they are respected for being older. In reply to such questions, almost all informants answered in the affirmative, describing how society treats them with respect when they are in the public space. The answers took the form of general statements: "All the people like me and respect me"; "I see that I'm paid respect by the way they look at me and speak with me"; "Everyone respects me and gives me a hug when I pass in the street"; "I'm always paid respect, every time I leave the house I'm given a free ride"; "Everyone who passes by asks how I'm doing." This is the public voice, describing in the most general terms the attitude toward older people in the Arab street.

However, later in the interview, when asked about relationships within their neighborhood and asked to share their personal experience of growing old and the way they are treated, the paradox surfaced. This voice tells a different story; it testifies to a lack of honor and respect and to a demeaning attitude, and is tinged with disappointment that respect today has diminished and sometimes does not exist at all. An informant, Abed, (aged 72), said: “They don't listen to what I say, they think I'm not lucid." Another informant, Omar described how a group of young people stood in the middle of the street and blocked his way and would not budge even when he asked them to move aside: "I have to ask them to move? Can't they see? It's because they don't take older people seriously like we used to do."

Sometimes the private-public distinction regarding honor and respect is made by differentiating between the informants' proximate surroundings - in my home, in my family, my children, my daughters, my village - where respect for older people is still the norm and the more distant surroundings - in another place, in a different village, among the others, in other families or among the Jews - where there is no longer any respect. An informant, Diana (aged 70), for example, said: "I once went to a wedding, in the village next to ours; the young girls that were there didn't even make room for me to sit. I don't know if it's a general lack of courtesy or lack of respect for my age. In my village something like that wouldn't happen." Similarly, the informant Abu Daoud (aged 86) stated: 
Ageing, ageism, and lost honor

The attitude towards older people has changed in recent years and it's a change for the worse, but in our village the values are still kept. Everybody knows everyone and there's an attitude of respect, but not like it once sons and daughters treat me with the utmost respect, but I know that others, not my children, see their parents as a burden.

The two voices of public and private are intertwined and cannot be separated. In the very same interview both the public and the private voice, describing a completely opposite experience, can be heard. These voices join together to create a narrative riddled with contradictions and dualities as regards society's attitude towards ageing and the treatment of older people. Remarks by Abu Daoud (aged 86) betray this internal contradiction: "I'm paid a lot of respect by the surroundings; I feel like a king, my age brings me respect, everyone wants to be close to me, I feel well-respected (...) Every place I go into they say hello to me, let me sit down, hear what I say." But later in the interview, as our conversation progresses and he feels more relaxed talking to me, he said:

Our society has changed; when someone young or a child passes beside an older person, he doesn't even say hello. It's indicative of a change for the worse. Our society has lost many of the good things that used to be in it. The attitude toward older people has changed. Today nobody is paid any respect. Not the older person, not the elders (...) What have we come to?

\section{Discussion: A Hybrid Discourse of Ageing between Tradition and Modernity}

This study has revealed the existence of ageism as expressed in the discourse and subjective experience of Arab elders in Israel. The discourse on aging shows that Arab culture, despite being traditional, demonstrates ageism and negative perceptions toward old age and older people. This finding is consistent with the findings of North and Fiske (2015) regarding the prevalence of ageism in Eastern cultures, sometimes even more so than in Western cultures.

The findings also indicate that some informants blame the influence of Jewish society, which is considered more Western and less traditional in its familial customs, for the decline in the status of elders. For example, the common practice in Jewish society of moving older people from their home to a facility is perceived by some of the informants as a deviant and 
International Journal of Ageing and Later Life

contemptible act and a terrible blow to the older person's honor. Many of the informants believe that living alongside Jewish society has undermined the status of older people and contributed to their loss of place in the family and in society at large. Moreover, in Arab society, unlike Jewish society, aged parents are usually supported by their adult children in terms of both financial and physical assistance in daily life. However, the increase in the numbers of women working outside the home and the pattern of urban living alongside Jewish society have made older people more of a burden on their family (Manor 2018). While respect for elders remains a central and important value, in practice it is difficult to implement.

This study has exposed that the contemporary discourse on aging lacks consistency and is replete with incoherence and internal contradictions regarding ageism and the value of respect for older people. This discourse, which developed in a very familistic society that emphasizes collectivist values and mutual commitment, reflects the changes taking place today in Arab society and the growing cracks in the delicate social fabric. The discourse is being conducted in two voices: the public and the private. The public voice describes the respect accorded elders in the public domain, in the Arab street, and is expressed in general statements such as: "Everyone in the street likes me and pays me respect." The private voice, on the contrary, describes personal experiences and feelings of disappointment at the lack of respect.

As shame plays a central role in Arab society, the public sphere has great significance in the daily conduct of the individual. The distinction between the public and the private arenas in the context of honor and ageism illustrates how in this aspect too there has been a change in Arab society's attitude toward older people. In other words, while one might expect respect for elders to be evident in the public domain, it has in fact been lost or, at least, eroded.

The two kinds of voices are tightly intertwined, constituting a hybrid discourse in which respect is intermittently both present and absent. They join together to create a narrative riddled with contradictions and dualities about honor and exclusion, pride and disappointment, and ageism and its absence. These contradictions reflect the informants' ambivalence toward the ongoing processes of change of Arab society in Israel, namely, acceptance of modernization and the influence of Jewish society 
Ageing, ageism, and lost honor

on the one hand and the desire to preserve traditional values on the other. The value of respect for older people in particular and the family in general remains a central value and one of the cornerstones of Arab society; however, the intrusion of Western norms and lifestyle undermines the status and honor of the aged.

Despite the accelerated changes and modernization processes that Arab society in Israel is undergoing, some have argued that it demonstrates relative tolerance toward ageing and traditional familial customs, such that family bonds are maintained and prioritized over other social ties (Bergman et al. 2013; Khalaila 2009). The current study, however, reveals a slightly different picture, in which old age is no longer accorded the same respect as in the past. Furthermore, acceptance of old age and ageing as a natural process, when it did surface in the interviews, was largely related to a religious conception of old age as an inevitable process and God's will but not as something desirable, conferring status and advantage. If old age does indeed bring with it honor and respect, then many should have been found to be looking forward to growing old. However, my findings attest otherwise, as does the suffering of old age described by Gilleard (2018). Many of the informants expressed a lack of interest in reaching an advanced age and a hope to die before that. This finding suggests that the status of older people has deteriorated and the respect accorded them has eroded. The aversion to growing old is largely connected to this change in perception and attests to new proliferating manifestations of ageism in Arab society.

The insights emerging from this study are that life alongside Jewish society and the processes of modernization experienced by Arab society have influenced the discourse of aging and turned it from a discourse based on respect and appreciation to one colored by ageism. The dominant narrative in the discourse of Arab old age attests to age and selfageism, and even though Arab society in Israel remains traditional and familistic, the issue of age has penetrated and caused cracks in the status of the elderly.

\section{Limitations of the Study}

The present study examined the subjective experience of older people in Arab society in Israel with the aim of characterizing the discourse dealing 
International Journal of Ageing and Later Life

with old age, honor, and ageism. In doing so, it does not, therefore, assess ageism systematically and quantitatively and future studies might therefore be conducted. Similarly, while the issue of gender did come up in some of the interviews with women, this was not my focus due to a lack of scope. Gender is, nonetheless, a topic deserving an in-depth examination, and I hope to address this in future research.

\section{Corresponding Author}

Shlomit Manor, Department of Sociology, Western Galilee College, P.O. Box 2125, Akko24121, Israel. Email: manor.shlomit@gmail.com.

\section{References}

Aboderin, I. (2004). Modernisation and ageing theory revisited: Current explanations of recent developing world and historical western shifts in material family support for older people. Ageing \& Society 24(1): 29-50.

Azaiza, F. \& Brodsky, J. (2003). The aging of Israeli's Arab population: Needs, existing responses and dilemmas in the development of services for a society in transition. The Israel Medical Association Journal 5: 383-386.

Azaiza, F. \& Croytoru T. (2010). A change in the status of the elderly in Arab society. In Y. Brick \& A. Lowenstein (eds.), The Elderly and The Family (pp. 75-89). Jerusalem: Eshel.

Bergman, Y. S., Bodner, E. \& Cohen-Fridel, S. (2013). Cross-cultural ageism: Ageism and attitudes toward aging among Jews and Arabs in Israel. International Psychogeriatrics 25(1): 6-15.

Bodner, E. (2009). On the origin of ageism among older and younger adults. International Psychogeriatrics 21(6): 1003-1014.

Bodner, E., Bergman, Y. \& Cohen-Fridel, S. (2012). Different dimensions of ageist attitudes among men and women: A multigenerational perspective. International Psychogeriatrics 24(6): 895-901.

Bodner, E., Cohen-Fridel, S. \& Yaretzky, A. (2011). Sheltered housing or community dwelling: Quality of life and ageism among elderly people. International Psychogeriatrics 23(8): 1197-1204.

Bourdieu, P. (1996). Understanding. Theory, Culture \& Society 13(2): 17-37. 
Ageing, ageism, and lost honor

Butler, R. N. (1969). Age-ism: Another form of bigotry. The Gerontologist 9: 243-246.

Butler, R. N. (1975). Why survive? Being old in America. New York: Harper and Row.

Central Bureau of Statistics (CBS) 2016. The Arab population of Israel. Population by religion No. 2.2 Available on http:/ / www.cbs.gov.il/reader/ newhodaot/hodaa_template.html?hodaa $=201711113$

Chi, I. (2011). Cross-cultural gerontology research methods: Challenges and solutions. Ageing \& Society 31(3): 371-385.

Chonody, J. \& Teater, B. (2016). Why do I dread looking old? A test of social identity theory, terror management theory and the double standard of aging. Journal of Women \& Aging 28(2): 112-126.

Cuddy, A. J., Norton, M. I. \& Fiske, S. T. (2005). This old stereotype: The pervasiveness and persistence of the elderly stereotype. Journal of Social Issues 61(2): 267-285.

Creswell, W. J. (2012). Qualitative inquiry and research design: Choosing among five approaches. London: Sage.

Denzin, N. \& Lincoln, S. (2008). Strategies of Qualitative Inquiry. Vol. 2. Thousand Oaks, CA: Sage.

Doron, I. (2008). Ageism and anti-ageism in supreme court rulings. Hamishpat 14: 25-37. (Hebrew).

Fogiel-Bijaoui, S. (2002). Familism, postmodernity and the state: The case of Israel. The Journal of Israeli History 21(1-2): 38-62.

Fraboni, M., Saltstone, R. \& Hughes, S. (1990). The Fraboni scale of ageism (FSA): An attempt at a more precise measure of ageism. Canadian Journal on Aging 9: 56-66.

Gamliel, T. \& Hazan, H. (2006). The meaning of stigma: Identity construction in two old -age institutions. Ageing \& Society 26(3): 355-371.

Gilleard, C. (2018). Suffering: The darker side of ageing. Journal of Aging Studies 44: 28-33.

Giorgi, A. (1997). The theory, practice, and evaluation of the phenomenological method as a qualitative research procedure. Journal of Phenomenological Psychology 28: 235-260.

Gliksman, A. \& Litwin, H. (2011). International spotlight: Israel. The Gerontologist 51(6): 734-738. 
International Journal of Ageing and Later Life

Hazan, H. (1994). Old Age: Constructions and Deconstructions. Cambridge:Cambridge University Press.

Hazan, H. (2002). Aging in the global village. In Y. Brik (ed.), Politics on Old Age (pp. 30-50). Tel-Aviv: HakibbutzHameuchd. (Hebrew).

Hazan, H. (2013). In praise of ageism: On the roots of flourishing discourse. In I. Doron (ed.), Ageism in the Israeli Society: The Social Construction of Old Age (pp. 52-66). Van Leer Jerusalem: HakibbutzHameuchd. (Hebrew).

Iversen, T. N., Larsen, L. \& Solem, P. E. (2009). A conceptual analysis of ageism. Nordic Psychology 61(3): 4-22.

Khalaila, R. (2009). Modernization and filial piety to elderly parents in Arab-Israeli society. Israel Gerontological Society 4: 77-98. (Hebrew).

Khalaila, R. \& Litwin H. (2012). Modernization and filial piety among traditional family care-givers: A study of Arab-Israelis in cultural transition. Ageing \& Society 32(5): 769-789.

Koren, H. (2013). What is it ageism? Structure and definition the concept. In I. Doron (ed.), Ageism in the Israeli Society: The Social Construction of Old Age (pp. 28-51). Van Leer Jerusalem: HakibbutzHameuchd. (Hebrew).

Lavee, Y. \& Katz, R. (2003). The family in Israel: Between tradition and modernity. Marriage and Family Review 34: 193-217.

Levy, B. R. (2001). Eradication of ageism requires addressing the enemy within. The Gerontologist 41(5): 578-579.

Levy, B. R. (2003). Mind matters: Cognitive and physical effects of aging self -stereotypes. Journal of Gerontology 58B(4): 203-211.

Litwin, H. (2006). The path to well-being among elderly Arab Israelis. Journal of Cross Cultural Gerontology 21(1): 25-40.

Litwin, H. \& Zoabi, S. (2003). Modernization and elder abuse in an ArabIsraeli context. Research on Aging 25(3): 224-246.

Löckenhoff, C. E., De Fruyt, F., Terracciano, A., McCrae, R. R., De Bolle, M., Costa, P. T., Aguilar-Vafaie, M. E., Ahn, C. K., Ahn, H. N., Alcalay, L., Allik, J., Avdeyeva, T. V., Barbaranelli, C., Benet-Martinez, V., Blatný, M., Bratko, D., Cain, T. R., Crawford, J. T., Lima, M. P., Ficková, E., Gheorghiu, M., Halberstadt, J., Hrebícková, M., Jussim, L., Klinkosz, W., Knezević, G., de Figueroa, N. L., Martin, T. A., Marusić, I., Mastor, K. A., Miramontez, D. R., Nakazato, K., Nansubuga, F., Pramila, V. S., Realo, A., Rolland, J. P., Rossier, J., Schmidt, V., Sekowski, A., 
Shakespeare-Finch, J., Shimonaka, Y., Simonetti, F., Siuta, J., Smith, P. B., Szmigielska, B., Wang, L., Yamaguchi, M. \& Yik, M. (2009). Perceptions of aging across 26 cultures and their culture-level associates. Psychology and Aging 24(4): 941-954.

Lomsky-Feder, E. \& Rapoport, T. (2007). Speaking their language? Estrangement, home and power relations in interviews with immigrants. Megamot 44: 636-654. (Hebrew).

Lowenstein, A. \& Katz, R. (2000). Rural Arab families coping with caregiving. Marriage \& Family Review 30(1-2): 179-197.

Lowenstein, A., Katz, R. \& Gur-Yaish, N. (2007). Reciprocity in parent-child exchange and life satisfaction among the elderly: Across national perspective. Journal of Social Issues 63: 865-883.

Macia, E., Lahman, A., Baali, A., Boetsch, G. \& Chapuis-Lucciani, N. (2009). Perception of age stereotypes and self-perception of aging: A comparison of French and Moroccan populations. Journal of Cross Cultural Gerontology 24: 391-410.

Manor, S. (2017). Trying to be someone you can never be again: Retirement as a signifier of old age. Ageing $\mathcal{E}$ Society 37(5): 985-1005.

Manor, S. (2018). There is nobody to rely on: Cracks in the intergenerational contract among the elders in Arab Society in Israel. Journal of Family Issues 39(11): 2935-2957.

Minichiello, V., Browne, J. \& Kendig, H. (2000). Perceptions and consequences of ageism: Views of older people. Ageing $\mathcal{E}$ Society 20(3): 253-278.

North, M. S. \& Fiske, S. T. (2015). Modern attitudes toward older adults in the aging world: A cross-cultural meta-analysis. Psychological Bulletin 141(5): 993.

Palmore, E. B. (1977). Facts on aging: A short quiz. Gerontologist 17: 315-320.

Palmore, E. B. (2001). The ageism survey: First results. The Gerontologist 41(5): 572-575.

Palmore, E. B. (2004). Ageism in Canada and the United States. Journal of Cross Cultural Gerontology 19: 41-46.

Rosencranz, H. A. \& McNevin, T. E. (1969). A factor analysis of attitudes toward aged. The Gerontologist 9: 55-59.

Rupp, D. E., Vodanovich, S. J. \& Crede, M. (2005). The multidimensional nature of ageism: Construct validity and group differences. The Journal of Social Psychology 145(3): 335-362. 
International Journal of Ageing and Later Life

Russell, C. (2007). What do older women and men want? Gender differences in the "lived experience" of ageing. Current Sociology 55: 173-192.

Smooha, S. (1990). Minority status in an ethnic democracy: The status of Arab minority in Israel. Ethnic and Recial Studies 13(3): 389-413.

Tajfel, H. (1981). Human Groups and Social Categories: Studies in Social Psychology. Cambridge, England: Cambridge University Press.

Tajfel, H. \& Turner, J. C. (1979). An integrative theory of intergroup conflict. In W. G. Austin \& S. Worschel (Eds.), The Social Psychology of Intergroup Relations (pp. 33-47). Monterey, CA: Brooks.

Tajfel, H. \& Turner, J. C. (1986). The social identity theory of intergroup behavior. Psychology of Intergroup Relations 5: 7-24.

Tornstam, L. (2006). The complexity of ageism: A proposed typology. International Journal of Ageing and Later Life 1(1): 43-68.

Tornstam, L. (2007). Stereotypes of old people persist: A Swedish "facts on aging quiz" in a 23-year comparative perspective. International Journal of Ageing and Later Life 2(1): 33-59.

Yun, R. J. \& Lachman, J. M. (2006). Perceptions of aging in two cultures: Korean and American views on old age. Journal of Cross Cultural Gerontology 21(1-2): 55-70. 